SECTION 6. Metallurgy and energy

Vyacheslav Semenovich Slavin

Doctor of Technical Sciences, Professor, FSEI HPE Nosov Magnitogorsk State Technical University slavin v s@,list.ru

Alexander Ivanovich Norets

Candidate of sciences in pedagogics, Assistant Professor, FSEI HPE Nosov Magnitogorsk State Technical University noretsa@mail.ru

Valentina Ignatovna Bilichenko Assistant Professor, FSEI HPE Nosov Magnitogorsk State Technical University cat138@yandex.ru

Vitaly Sergeevich Panteleev MA student FSEI HPE Nosov Magnitogorsk State Technical University

UDC 621.778.1.073 momzmstu@mail.ru

\title{
EFFICIENCY INCREASE OF SHAPES DRAWING PROCESSES DUE TO THE ROLLER DIES APPLICATION
}

Abstract: The article describes efficiency increase of technological schemes of producing profile shapes from ferrous and non-ferrous metals by using roller dies considered by the example a calibrated steel hexagon and a contact wire. Describes the advantages of using a housingless roller dies and their dual sets, given examples of their effective use in the industry. sections.

Key words: roller drawing dies; drawing dies housingless type; drawing of shaped

Metal deformation processes in the calibers formed by two or more non-driven rollers are more often used when developing new technological schemes of shapes production by drawing. This is connected with advantages of drawing in roller dies in comparison with monolithic dies, caused by replacement of the sliding friction by the rolling friction. And this is also connected with the possibility of technological operations reduction at the expense of more favorable deformation conditions over the whole billet perimeter.

We will consider the advantages of various economically effective design schemes of drawing on the examples of producing from round billets the calibrated steel hexagon in accordance with GOST 8560-78 and a contact copper conductor and copper alloys in accordance with GOST 2584-86.

Currently for production of a calibrated steel hexagon different technological processes are used in hardware industry. The most widely applied is the method of drawing in monolithic dies. Hot rolled hexagonal or circular blanks are usually used as a billet.

As a rule, when a hot rolled hexagonal is used the finished product is produced by drawing for one pass. Low economic efficiency of this technological process is connected: with the billet's high cost, a relatively low resistance of the expensive tool (com-pared with drawing a calibrated circle) and the need of "freezing" of current assets for acquisition of special billets for all the range, both according to standard sizes, and according to steel grades.

Application of the unified round section billets reduces expenditure for its acquisition and storage, however in that case the expenses for the drawing process are significantly 
increased as the final product is obtained after a few passages. Moreover, for some metals additional annealing and surface preparation for drawing are required.

One of the most effective ways to eliminate the disadvantages mentioned above is the use of drawing in dies with multi-roller caliber. Various technological schemes of receiving the ca-librated steel hexagon from a round billet with application of the roller dies of various designs are used at hardware plants of ferrous metallurgy.

There is a well known drawing process in which the leader dimensions of a hexagon are produced in a closed three-roll die caliber but the finishing pass is carried out in a monolithic die [1, p.65]. However the application of the closed type caliber imposes additional restrictions to size tolerances of the used billet because at caliber overflow on the intermediate shape surface the defects in the form of "whiskers" may appear, and if the caliber is not enough filled up the insufficient work up of the finished section faces is possible.

The technology is also known according to which the formation of the hexagon leader dimensions from a round billet is carried out in the die with displaced couples of rollers, and the finished precise dimensions - in a monolithic die [2, p.36]. Thus drawing can be carried out in one pass with obtaining finished dimensions or separately in two passes. The roller die calibration sys-tem is a rhombus in the first pair of rolls and a smooth barrel in the second pair of rolls. The disadvantage of this process is the instability of the geometric dimensions of the shape circle due to the calibration system and the reduction of physical and mechanical properties of the finished product due to unevenness of the step deformation scheme.

The most effective, in our opinion, is the three-stage deformation scheme with application of three-roller calibers in one pass (fig. 1). Formation of the hexagon leader dimensions from a round billet is carried out in three-roller calibers of the first 2 and the second 3 deformation steps constructed according to the system: a triangle - the triangle with rotation around the axis at the angle of $60^{\circ}$. The finishing dimensions of the finished product are formed in the monolithic die 4 in the third deformation step for one pass. The advantage of this scheme is the uniform distribution of reduction between the first stages of deformation which provides increase of physical and mechanical properties of the finished metal product [3, p.385]. The system of calibers consisting of the first two deformation stages: a triangle $-\mathrm{a}$ triangle makes it insensitive to the choice of the initial billet diameter, and the total deformation (up to 40-45\%) is limited by the requirements of physical and mechanical properties of the finished product. The back tension created by metal deformation at the first two steps of billet forming provides increased resistance of the monolithic die and a significant decrease of energy consumption.
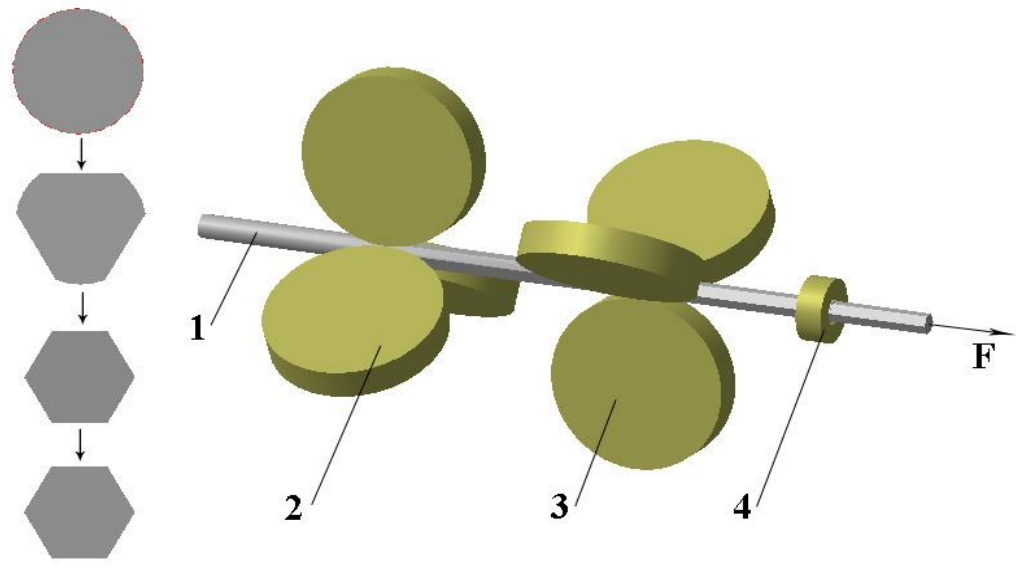

Figure 1 - The scheme of three-stage deformation for one pass.

For implementation of the developed technological scheme of producing the calibrated steel hexagon at the JSC "MMK-Metiz" (Magnitigorsk) dual sets of the housingless roller dies were developed for drawing lines and finishing bars of the type 1026 and 1028 
produced by the Irkutsk plant of heavy mechanical engineering. It was planned to produce a calibrated steel hexagon with wrench sizes from 8 to $17 \mathrm{~mm}$ on the line 1026 (Fig. 2), and on line 1028 - with wrench sizes from 18 to $27 \mathrm{~mm}$. It should be noted that the compactness of dual roller die kits sizes permits to install them on drawing machines from other manufacturers without significant alterations.

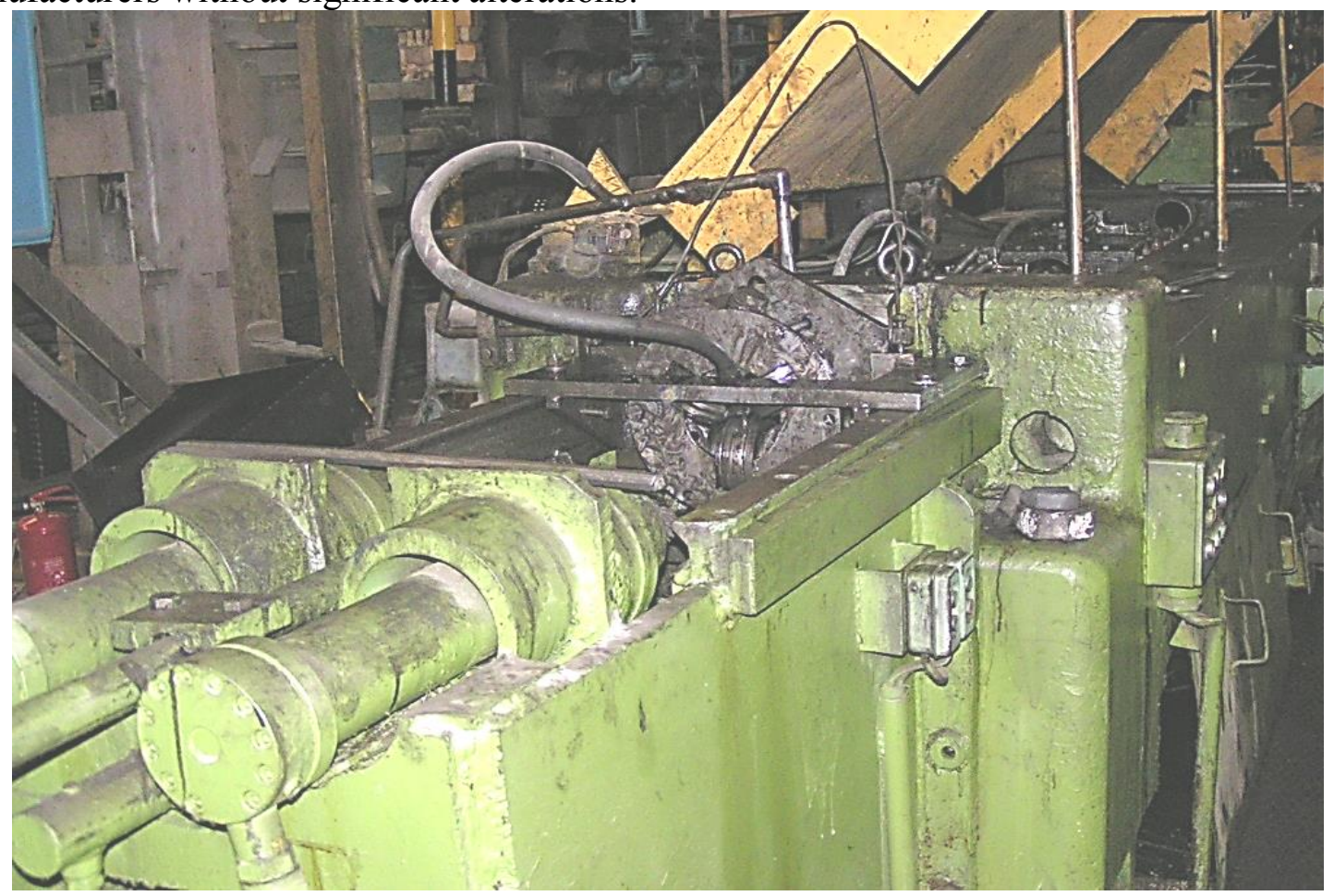

Figure 2 - Line for drawing and finishing bars with dual set of the housingless roller dies.

Experience in the production of calibrated steel hexagon in accordance with GOST 8560-78 using the developed scheme of forming a circular blank and housingless roller dies confirmed its economic efficiency and validity [4, p.91].

We will consider creation of the new arrangement scheme of contact wire drawing from copper and its alloys in accordance with GOST 2584-86.

The traditional known scheme of production of a contact wire (fig. 3) represents formation of a finished product for five passes [5, p.136].

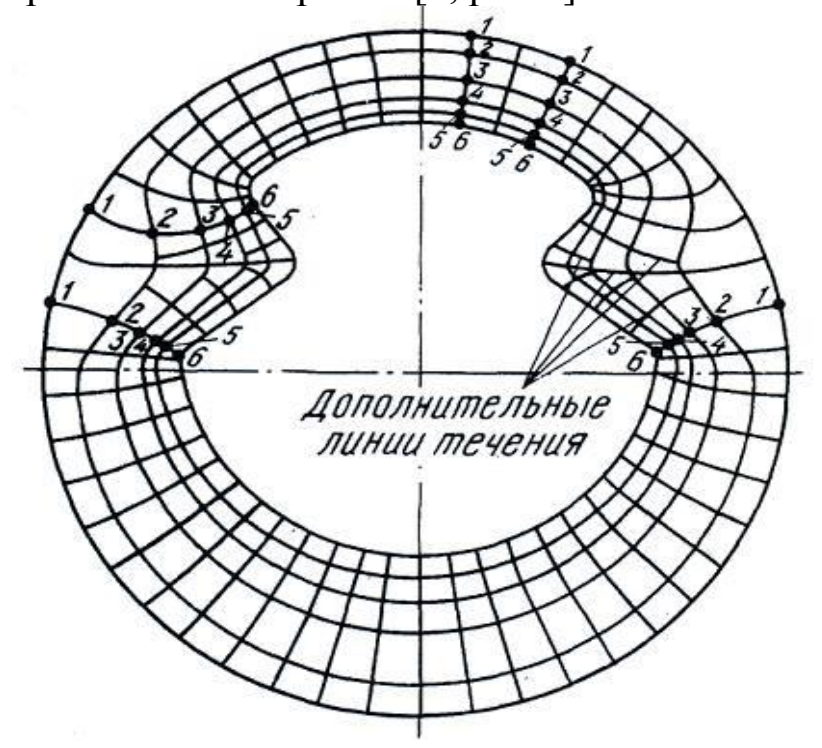

Figure 3 - The traditional scheme of production of a contact wire. 
A significant number of transitions is associated with high local deformations where it is difficult to supply lubricants which have the following consequences: low tool life, deterioration of the finished product quality, high energy costs. In order to provide the required accuracy of each pass rigid billet orientation must be respected which determines the complexity of the process.

When drawing a contact wire from copper and its alloys the most effective is the twostage scheme with application of roller dies with a three - and four-roller caliber (fig. 4) which provides formation of a finished profile for one pass [6, p.302]. In this case the leader pear-shaped profile is obtained at the first stage of deformation, and at the second deformation stage the ready shape with finished dimensions is produced.
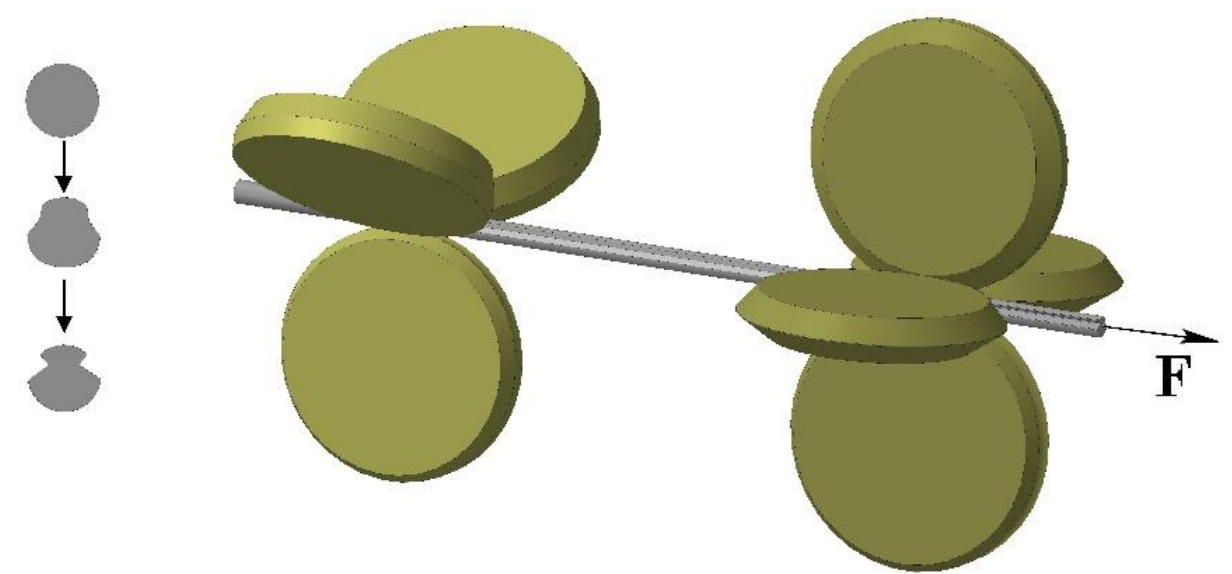

Figure 4 - The two-stage scheme with application of roller dies.

The conducted laboratory researches of the shape MF-100 formation in accordance with GOST 2584-86 showed that the proposed arranged scheme can improve the physical and mechanical properties of the finished product, significantly increase the resistance of the drawing tool and reduce energy costs.

For ensuring the production of shapes in roller dies according to the described schemes, and also for production of other types of shapes we created and tested various designs of housingless roller dies in which calibers are formed by three and four rollers. On the basis of the conducted researches a parametrical row of housingless roller dies with three - and four-roller calibers and also with the displaced couples of rollers [7, p.124; 8, p.158] was constructed for drawing of the shapes with various areas of cross section from 0,5 to $1800 \mathrm{~mm}^{2}$. For expansion of an assortment and increase of the produced products accuracy due to metal deformation on all the billet perimeter the dual sets of roller dies with three - and four-roller caliber were created.

Advantages of housingless roller dies over the existing analogs are as follows: high caliber rigidity, providing the required accuracy of the final product, and the compactness of design that permits to make use of the existing-drawing equipment without essential reconstruction.

In addition, the developed roller dies design permits to create a variety of two-and three-stage schemes of drawing with the use of monolithic dies:

- a roller die - a roller die;

- a roller die - a monolithic die;

- a monolithic die - a roller die;

-a roller die -a roller die -a monolithic die.

Such schemes provide the use of both drawing modes ad-vantages. 
The dual sets of roller dies in the combination only with three - or four-roller calibers are often used for producing a shape of the round section from a round billet, a cold-drawn reinforcing wire with higher requirements to the shape cylindrical parameters. In certain cases the combination of three and four-roller calibers will allow to increase technological effectiveness of producing the shaped profiles of complex forms.

Thus, the technological and economic feasibility of various arrangement schemes of shapes drawing with the use of the housingless roller dies is presented on examples of producing the calibrated steel hexagon and the contact wire from copper and its alloys.

\section{References:}

1. Malikov A.G., Demura Y.A., Zubko T.V., Klimova V.N., Ilyukovich B.M. Effektivnaya tekhnologiya proizvodstva shestigrannoi kalibrovannoi stali iz kroglogo podkata. [The effective technology of production the calibrated steel hexagon from round billet]. Stal'. [Steel], 1992, no.9, pp. 65-67.

2. Kol'chak V.S., Ribkin A.V., Nikitina L.A., Nikitina G.P. Osvoenie proizvodstva shestigrannikh prutkov iz legirovannikh stalei. [Development of production of hexagon bars from alloyed steels]. Stal'. [Steel], 2002, no.5, pp. 36-37.

3. Patent no. 2235614 (RF, B21C1/00) Slavin V.S., Platov S.I., Antsupov V.P., Panteleev V.S., Urtsev V.N., Shtol V.Y. Sposob polucheniya kalibrovannogo shestigrannogo profilya. [Method of production of calibrated steel hexagon profile]. Bulletin izobretenii $i$ poleznikh modelei. [Official Bulletin of Inventions and Utility Models], 2004, no. 25.

4. Slavin V.S., Vershigora S.M., Panteleev V.S. Kombinirovannaya tekhnologicheskaya schema proizvodstva kalibrovannogo shestigrannogo prokata. [Combined production flowsheet calibrated steel hexagon]. Stal'. [Steel], 2007, no.2, pp. 91-93.

5. Ermanok M.Z., Vatrushin L.S. Volochenie tsvetnikh metallov i splavov. [Drawing of nonferrous metals and alloys]. Moscow: Metallurgy, 1988, $288 \mathrm{p}$.

6. Patent no. 2492010 (RF, B21C1/00) Slavin V.S., Norets A.I. Sposob volocheniya provoda kontaktnogo iz medi i ee splavov. [The method of drawing contact wire from copper and its alloys]. Bulletin izobretenii i poleznikh modelei. [Official Bulletin of Inventions and Utility Models], 2013, no. 25.

7. Slavin V.S. Rolikovie voloki s mnogovalkovim kalibrom besstaninnogo tipa. [The housingless roller dies with multiroll caliber]. Nauka i tekhnologii. Tom 2. Trudi XXVI Rossiiskoi shkoli. [Science and Technology. Volume 2. Proceedings of the XXVI Russian school]. Moscow: Russian Academy of Sciences, 2006, pp. 115-126.

8. Slavin V.S. Rolikovie voloki besstaninnogo tipa. [The housingless roller dies]. Magnitogorsk: Magnitogorsk State University, 2010, 169 p. 